\title{
DIGITAL APPS IN FORMATIVE ASSESSMENT: TODAY'S AID IN TEACHING AND LEARNING IN HIGHER EDUCATION
}

\author{
Dr. John M. Zamen \\ Lecturer in Economics,Monash College, Melbourne, Australia
}

Article DOI: https://doi.org/10.36713/epra4010

\begin{abstract}
Assessment is an extensive topic that encompasses a wide variety of definitions within the field of education, and evaluating the effectiveness of many types of assessment is often an arduous task.

Master, G. 2015 stated, "The fundamental purpose of assessment in education is to establish and understand the points that students (either as individuals or groups) have reached in their learning at the time of assessment'.

Assessment is the process of gathering data. More specifically, assessment is the way instructors gather data about their teaching and their students' learning (Hanna, G and Dettmer, P, 2004). There are many different forms of assessment, each with their own specific purpose. Determining what kind of assessment is most effective is highly dependent on the purpose of the data a teacher is trying to collect. Since assessment is often used in making major decisions, there is a great deal of discussion regarding strategies that could improve student performance.

Trends in formative assessment and using data to positively impact student learning has become an integral part of a teacher's everyday and ongoing practice.

This article addresses formative instructional practice and the many strategies, techniques and tools available to both teachers and students. These tools and apps give teachers and students many options and opportunities for classroom success.
\end{abstract}

KEYWORDS: Formative assessment, summative assessment, assessment of learning, formative assessment apps.

\section{INTRODUCTION}

What is Formative Assessment?

Traditional instructors of my school and college days wayback in late 1960's used Summative assessments, such as mid- term or half yearly exams, end of term or semester or final or yearly exams, to determine at a point in time what students knew and did not know. Such assessments have high stakes, which mean that they have a high point value. The goal of summative assessment is to evaluate student learning at the end of an instructional unit by comparing it against some standard or benchmark.

However, instructors like me are now using Formative assessment in an ongoing process, designed (a) to assess where a student is in the learning process and (b) to help a teacher use student's responses to determine the instructional activities necessary to further enhance the student's learning. Formative assessment is an assessment method that teachers can use in real-time to gather information regarding the student's current level of understanding. Furthermore, formative assessments (a) help students to identify their strengths and weaknesses and target areas that need focus and need more attention or work (b) help teachers and faculty to recognize where students are struggling and address problems immediately. The process allows students who are struggling with earlier remedial interventions before they lag behind their peers. If students are not challenged enough, they will become bored and it is unlikely that teachers will be able to further stimulate student thinking to foster student growth. (Heritage, 2007). 


\section{EPRA International Journal of Research and Development (IJRD)}

Formative assessment must focus on the students and the activities in which the teacher daily engages them in the classroom. (Williams, 2007).

"Formative assessment is a systematic process to continuously gather evidence about learning". (Heritage, 2007, p2).

According to study conducted by Furtak et al., (2016, p267), formative assessment can be categorised into 4 parts: "designing formative assessment tasks, asking questions to elicit student thinking, interpreting ideas, and providing feedback that moves student thinking forward".

Formative assessments are generally low stakes, meaning they have low or no point value. It is more of a diagnostic nature rather than focusing on evaluation or grading. Findings have shown that both students and instructors benefit from regular, ongoing assessment when it is used to "promote and diagnose" learning (Huba and Freed, 2000).

\section{Why Formative Assessment matters?}

Formative assessment is a part of teaching and instructional process. It is a flexible and informal way of assessing students' progress and their understanding of particular subject matter. Formative assessment monitors student learning, but also provides feedback, not only to the learner (student) but also to the teacher (instructor). When incorporated into classroom teaching and instructional practice, it provides appropriate information required to adjust and modify teaching and learning while they are happening. These adjustments help to ensure students achieve target standards based on learning goals within a set time frame, and students begin to differentiate between what they already know and what they need to learn.

\section{How Formative Assessments Strategies different from Summative Assessments?}

"To really succeed, however, students must learn to self-assess so that they can understand the main purposes of their learning and thereby grasp what they need to do to achieve" (Black and William, 1998).

1. Formative assessment allows for practice and helps teachers determine and make adjustments during the learning process.

2. For formative assessment to be effective, student must be actively involved in the process. If student are not involved in the assessment process, formative assessment will lose complete effectiveness. Students need to be involved both as assessors of their own learning and as resources to their peers. Many researches show that the involvement and taking ownership of their learning increases students' motivation to learn. On the other hand, the teacher's involvement is crucial in identifying learning goals, setting clear criteria for success and designing assessment tasks that provide evidence of student learning.

Providing descriptive feedback in the process of learning promotes positive student engagement. Descriptive feedback provides students with an understanding of what they are doing well, links to the classroom learning, and provides specific input on how to reach the next step in the learning process.

\section{TYPES OF FORMATIVE ASSESSMENT STRATEGIES}

Some of the quick ways to check for students' understanding and to gather "evidence" of their learning in the classroom in real time are as follows:

Active Learning: Asking questions after teaching a part of lesson provides immediate feedback to instructors and students as to how well they have understood the concept.

In-class Quiz: Short in class quizzes. Can be used either pre or post teaching of a topic.

Exit Slips: (written responses to a question or questions an instructor poses at the end of the lesson) asking students to answer a question that targets the main idea of the lesson taught.

In class Survey: Behavioural attitudes of the learning can be assessed through class surveys regarding the effectiveness of teaching and learning of the lesson or topic of subject matter.

List, Charts and Graphic Organizers: Organizing information, making connections and noting relationships by use of various graphic organizers.

Collaborative Activities: Providing an opportunity to move and/or communicate with others in group activity as they develop and demonstrate their understanding of the concept taught.

Collage/Poster: Students make a collage or poster demonstrating their understanding of the concept individually or as a group activity.

Talk-it-Out/ Presentation: Students host their own talk show or class presentation to discuss the important points of the lesson.

\section{KEEPING TRACK OF DATA GATHERED FROM MULTIPLE SOURCES}

When using formative assessments, teachers must keep track of the data collected during the learning process. An ideal approach would be to create a class folder for each student along with notes of their performance. This process will help to focus on the needs of individual students when providing feedback to each student or develop lessons for the whole class. Assessments enable teachers to determine what students need. But for the 
assessments to be accurate, teachers need multiple measures of students' understanding. Teachers need evidence gathered over time in different ways to evaluate how effective the teaching and learning process has been. Tomlinson and McTighe (2006) suggest that we gather a "photo album" rather than a "snapshot" of our students'. We can differentiate instruction based on a more accurate evaluation on our students' learning needs.

\section{APPS TO SUPPORT FORMATIVE ASSESSMENT ACTIVITIES}

Formative assessment activities should be quick, enjoyable and versatile. Formative assessment is best when it IS ongoing and consistent. Here is a list of some useful formative assessment apps that are creative, low tech, fun and engaging for students and easy for a teacher to implement on a daily on- going basis.

- AnswerGarden: A tool for online brainstorming or polling. Teachers can use this real-time tool to see student feedback on questions.

- Answer Pad: A graphical student response system with the ability for polling and leave feedback. The blank pad functions act as an individual whiteboard for each student.

- Buncee: A creation and presentation tool that helps students and teachers visualize, communicate, and engage with classroom concepts and ideas.

- ClassKick: This app allows teachers to post assignments for students, so both the teacher and peers can provide feedback on the assignment. Students can monitor their progress and work.

- Coggle: A mind- mapping tool designed to understand student thinking.

- Educreations Interactive Whiteboard: A whiteboard app that gives students a tool to share their understanding and comprehension.

- ForAllRubrics: This software is free for all teachers and allows to import, create, and score rubrics on ipads, tablets, or smartphones. Data can be collected, compute scores automatically, print and save the rubric as a Pdf or spreadsheet.

- Formative: This online response system provides teachers the opportunity to assign activities to students, receive the results in real time, and then provide immediate feedback to students.

- Formative Feedback for Learning: An ipad app that is designed to foster and encourage communication between students and teachers. Through a conference setting, it uses icons to prompt discussions.

- Google Form: A Google Drive app that allows to create documents that students can collaborate in real time using smart phones. tablets and laptops, Bring Your Own Device (BYOD).

- Kahoot: A game based classroom response system, where teacher can create quizzes using their own resources and internet content.

- Kaizena: An online tool for providing students with real time feedback on their digitally uploaded work. Teachers can highlight or speak to give verbal feedback and attach teacher created, reusable resources to student work.

- Naiku: Teachers can easily and quickly create quizzes that students can answer using their mobile devices. A great tool for checking pre and post class understanding.

- Obsurvey: Create surveys, polls and questionnaires quickly and easily.

- Padlet: Provides an essentially blank canvas for students to create and design collaborative projects or can be used as brain storming activities.

- Pear Deck: Plan and build interactive presentations that students can participate in via their smart devices.

- PollDaddy: Quick and easy way to create online polls, quizzes and questions. Students can use smartphones, tablets and computers to provide their answers, and information collected can be analysed for reports.

- Poll Everywhere: Teachers can create a feedback poll or ask questions. Students respond in various ways and teachers see the result in real time. With open ended questions, you can capture data and tag aggregate responses.

- ProProfs: Build and test knowledge with quick quizzes, polls and surveys.

- RealtimeBoard: Teachers can invite students and collaborate with the whole class in real time.

- Quia: Teachers can create games, quizzes, surveys and many more activities, as well as access a database of existing quizzes from other educators.

- Quizlet: Create flashcards, tests, quizzes and study games that are engaging and accessible online and via mobile devices.

- Socrative: A great tool having variety of activities such as quizzes, exit ticket and 
games that engage students using smartphones, laptops and tablets.

- Triventy: A free quiz game platform that allows teachers to create quizzes that students take in real time. These live quizzes provide teachers with real time data on student understanding of topic or concepts taught. Student use BYOD.

- Vocaroo: A free service that allows users to create audio recordings without the need for software. Recording can be embedded into slide shows, presentations, or websites. Great tool for collaborative activities.

- Yacapacal: Allows teachers to easily create quizzes on the fly.

\section{ILLUSTRATION}

In my Tutorial classes of MCD 2020 (Microeconomics) and MCD 2090 (Macroeconomics) at Monash College, Melbourne, Australia. I have been using formative assessment as an integral part of my teaching practice. I use many formative assessment apps and digital tools, which are quick, easy and versatile to check for student understanding of the concepts or topic taught.

Attached is a screenshot of one of the activities conducted in one of my Tutorial groups, using an app - Socrative (Fig.1.) and (Fig. 2). Socrative is a free tool for students and teachers. Teachers create an account and are able to design quizzes ahead of classes. Teacher have options to push multiple- choice questions or give a blank space to answer a question or use it as an exit slip, (feedback survey). These are indeed nice and flexible options for teachers to check students understanding of the day's concepts taught. The teacher can visualize the data in real time, and all responses are arranged in a spreadsheet, making it easy to get a full picture of the entire class understanding of the particular topic taught. The activity helps students to identify their performance (strengths and weaknesses) and target areas that need further work and reinforcement. It also helps teachers to recognize where students are struggling and address problems immediately. Teachers can use the data to provide critical feedback to students. Furthermore, as the learning journey progresses, the formative assessments indicate whether the teaching strategy/ plan needs to be revised, modified or reinforces to improve learning outcomes or to intervene to support those students who need additional support.

\section{CONCLUSION}

To see whether students are meeting the required standard of understanding, Summative assessment is conducted after a certain time- period to determine how much learning has taken. Grades are ascribed to students' learning at the end of term or quarterly or in half yearly exams to provide accountability of learning. On the other hand, Formative assessment support learning during the learning process and is considered a continuous part of learning, it need not be graded as summative examinations. Rather it serves as practice for students, to check for understanding along the way and guide teacher decision making about future teaching instruction, and also provide feedback to students so they can improve their performance. Ideally, both the teacher and the student gain information from the assessment and use it collaboratively to plan future learning activities. Formative assessments are quick to conduct on a daily basis and do not take an inordinate amount of time. The time taken from the lesson is well worth the information teacher gathers and the retention students gain. Indeed, digital apps in formative assessment are an ideal aid in teaching and learning.

\section{REFERENCES}

1. Black, P. \& Dylan, W. (1998). "Assessment and Classroom Learning”. Assessment in Education: Principles, Policy, and Practice 5 (March 1998): 7-74.

2. Dylan, D. (2007)." Keeping Learning on Track: Formative Assessment and the regulation of Learning". In Second Handbook of Mathematics Teaching and Learning, edited by Frank $K$. Lester Jr., pp 1053-98. Greenwich, Conn: Information Age Publishing.

3. Furtak, E.M., Kiemer, K., Circi, R.K., Swanson, $R$., de Leon, V., Morrison, D., \& Heredia, S.C.(2016). Teachers' formative assessment abilitiies and their relationship to student learning : Finding from a four-year intervention study. Instructional Science, 44(3), 267-291.

4. Hanna, G.S., and Dettmer, P.A. (2004). Assessment for reflective teaching: Using contextadaptive planning. Boston, MA: Pearson $A \& B$.

5. Heritage, M. (2007). Formative assessment: What do teachers need to know and do? Phi Delta Kappan, 89(2), 140-145.

6. Master, $G$ (2015). 'Rethinking formative and summative assessment' ACER. 


\section{FIGURES}

Supply, demand and government policies Week 5 Session 1 - Mon Mar 25 2019

\begin{tabular}{|c|c|c|c|c|c|c|c|c|c|c|c|c|}
\hline & Shaw Nismes & & tow / pros & & & & & & & & & \\
\hline Here & Name 7 & Soore $(8) \quad \boldsymbol{V}$ & 1 & 2 & 3 & 4 & 3 & 6 & 7 & 8 & 9) & 10 \\
\hline$\theta$ & Notst & $100 \mathrm{n}$ & The: & Fulite & Thut: & Falie & Falle & The & filtas & The & Fabe & Fathe \\
\hline (2) & ...... & $700{ }^{\prime}$ & this & Palies & thue & The & shest & False & Fes & tous & Balue & The \\
\hline (2) & Not.t. & $30 \mathrm{~N}$ & Thus: & Thue: & Tran & Falle & & & & & & \\
\hline (2) & A**** & $100 \%$ & trus: & Falite & tovin & Eatie & false & thise & Fthere & trive & False & False \\
\hline (ㄱ) & ntst. & $40 \%$ & Phus & Pake & tring & False & & & & & & \\
\hline (8) & N*** & 9091 & Irue: & fatse & Trus & Falte: & True & Trie & fath & Trues & Sates & Fathe \\
\hline Q & At+te & ov & & & & & & & & & & \\
\hline (c) & (n... & $50 \%$ & False & Filte & True & Falie & Palse & Tine & frats & inne & Falso & Faber \\
\hline (C) & ..... & $40 \%$ & This: & Fahr & Trun & Fohe & & & & & & \\
\hline (2) & N.t.t. & $80 \mathrm{n}$ & the & Bube & Irute & Falte & Fillse & The & Folse & Fabe & Palse & \\
\hline (3) & Not. & som & Thus & Finte & Trun & Fithe & Fivise & Trie & Fine & Palse & rithe & Tathe \\
\hline 8 & totst & 800 & Thr: & Fulier & Thut: & Falie & Falst & The & Fithe & False & Fabe & True \\
\hline (C) & An. & $90 \%$ & these & Falie & true & Balle & True & the & stive & 790 & ratue & Fohe \\
\hline (3) & N...* & $\cos$ & Talse: & Fulse & TruH & Falie & True & The & ritse & The & & \\
\hline (8) & N*n** & $30 \%$ & trut & Trise & Truit: & Batic & & & & & & \\
\hline (2) & n... & 904 & Thus & falles & tove & Falles & then & ituse & Folat & Fakn & Fathe & False \\
\hline (9) & ntw. & 3035 & Irue & Fatie & Falsen & Fatic & & & & & & \\
\hline (1) & H.t. & 900, & true & Fabie & Trut & Falie & Filst & The & Fites & Thie & False & \\
\hline (9) & ...... & $80 \%$ & Truse: & Falte & Faloe & Falie & Fails & Tine & Fonts? & Fabe & False & Fatse \\
\hline (C) & ANtr & $90 \mathrm{~h}$ & Thu: & Fabe & Thun & Falhe & Filate & The & Finte & Fatse & Fation & Fathe \\
\hline (2) & N.t. & som & Tave & Fibe & True: & Balie & Fulse & The & Folse & Thus & Polue & True \\
\hline (C) & ntst. & som & Thus & ratle & Thu & Fille & Fitat & Trie & fritsen & rake & riake & Tatse \\
\hline (3) & totst & $90 \mathrm{~h}$ & Din: & Fullie & Thus: & Falie & Fallit & Tris & fill & The & Fabe & True \\
\hline (C) & Ant* & $60 \%$ & Fils & Fater & Fristi & Balle & Trun & then & fere & thes & Folus & These \\
\hline (9) & N*w* & $100 \mathrm{~N}$ & Then: & ranke & Truit & Falie & Fulse & Trese & Finge & The & Folue & Fallor \\
\hline 25 & Class Yotal & & Bass & 9296 & $88 \%$ & 9eet & 795 & $95 \%$ & $100 \%$ & 639 & $100 \%$ & 69: \\
\hline
\end{tabular}

Fig.1: (MCD 2020) -Multiple Choice /True or False or Short Answer Quiz , students complete in real time on their device, to check understanding of the topic taught. 


\section{Exit Ticket Quiz - Mon Apr 012019}

\begin{tabular}{|c|c|c|c|c|c|}
\hline & Show Names & & low An & & \\
\hline Here & Name $\uparrow$ & Score $(\%) \quad \boldsymbol{V}$ & 1 & 2 & 3 \\
\hline & $* *+* * *$ & $100 \%$ & A & 45 degre & The $45 \mathrm{~d}$ \\
\hline & 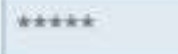 & $100 \%$ & A & aggregat & C: purch \\
\hline & $* * * * *$ & $0 \%$ & C & some for & A solid \\
\hline & 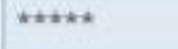 & 096 & B & we learn & when the \\
\hline & $k * * * *$ & $0 \%$ & B & 1. what & macroeco \\
\hline ( & w.t*t & 096 & B & Today I & The $45^{\circ} 1$ \\
\hline & $* * * * *$ & $0 \%$ & B & The aggr & The 451 \\
\hline ( & $\ldots \ldots *$ & $100 \%$ & A) & AE graph & macroeco \\
\hline & 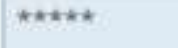 & $0 \%$ & B & aggregat & the use \\
\hline & *n** & $0 \%$ & B & $\mathrm{AE}=\mathrm{C}+\mathrm{H}+$ & The GDP \\
\hline & $* * * * *$ & $0 \%$ & C & Understa & All poin \\
\hline 4 & $* * \pm * t$ & $100 \%$ & A & LR growt & the equi \\
\hline & $* * * * *$ & $100 \%$ & A & Learning & The $45^{\circ} \mathrm{I}$ \\
\hline & $4+\infty+\infty$ & $100 \%$ & A & the AE m & macroec \\
\hline & $* * * * \star *$ & $100 \%$ & A & We learn & Macroeco \\
\hline & w.t. & $100 \%$ & A & aggregat & the $45 \mathrm{~d}$ \\
\hline & ****** & $100 \%$ & A & aggregat & real gdp \\
\hline & $\ldots \ldots *$ & $0 \%$ & & & \\
\hline & *n+kt* & $0 \%$ & B & I learn & As real \\
\hline & 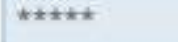 & $0 \%$ & & & \\
\hline 2 & $* * 0 * *$ & $0 \%$ & B & Long run & The AEI \\
\hline D & t+t+t*t & $0 \%$ & B & Aggregat & The equi \\
\hline ( & 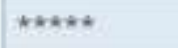 & $0 \%$ & B & Macroeco & At point \\
\hline 23 & Class Total & & $43 \%$ & & \\
\hline
\end{tabular}

Fig. 2. Exit Ticket (MCD 2090) - students reflection of the topic taught at the end of the lesson. There are two inbuilt questions in the app itself (1. How well did you understand today's material? The student's have the options A. Totally got it B. Pretty well C. Not very well D. Not at all. 2. What did you learn in today's class?) The teacher sets the Third Question, orally or on the Board, such as to explain/describe/illustrate some concept or theory learnt in the day's topic, 